Amgen, BMS, Celgene, Genentech, Janssen, Lilly, Novartis, Pfizer and UCB, Bruce Kirkham Grant/research support from: Abbvie, Janssen, Lilly, Novartis, Roche, UCB, Consultant for: Abbvie, Janssen, Lilly, Novartis, Roche, UCB, Speakers bureau: Abbvie, Janssen, Lilly, Novartis, Roche, UCB, Alejandro Balsa Grant/research support from: Abbvie, Pfizer, Novartis, BMS, Nordic, Sanofi, Consultant for: Abbvie, Pfizer, Novartis, BMS, Nordic, Sanofi, Sandoz, Lilly, Paid instructor for: Pfizer, Speakers bureau: Pfizer, Novartis, UCB, Nordic, Sanofi, Sandoz, Lilly, Atul Singhal Grant/ research support from: AbbVie, Gilead, Sanofi, Regeneron, Amgen, Roche, BMS, Janssen, Lilly, Novartis, Pfizer, UCB, Astra Zeneca, Medlmmune, FujiFilm, Nichi-lko, Mallinckrodt, Speakers bureau: AbbVie, Erhard Quebe-Fehling Shareholder of: Novartis, Employee of: Novartis, Luminita Pricop Shareholder of: Novartis, Employee of: Novartis, Corine Gaillez Shareholder of: Novartis, BMS, Employee of: Novartis DOI: 10.1136/annrheumdis-2019-eular.2531

\section{FRI0458 THE RISK FOR PSA: RESULTS FROM THE INCIDENT HEALTH OUTCOMES AND PSORIASIS EVENTS PROSPECTIVE COHORT STUDY}

Alexis Ogdie $^{1}$, Daniel Shin ${ }^{1}$, Hyon Choi $^{2}$, Christopher T. Ritchlin ${ }^{3}$, Joseph F. Merola ${ }^{4}$, Jose Scher ${ }^{5}$, Thorvardur Jon Love 6 , Joel Gelfand ${ }^{1} .{ }^{1}$ University of Pennsylvania, Philadelphia, PA, United States of America; ${ }^{2}$ Massachusetts General Hospital; Harvard Medical School, Boston, MA, United States of America; ${ }^{3}$ University of Rochester, Rochester, NY, United States of America; ${ }^{4}$ Brigham and Women's Hospital; Harvard Medical School, Boston, MA, United States of America; ${ }^{5}$ New York University, New York, NY, United States of America; ${ }^{6}$ University of Iceland, Reykjavík, Iceland

Background: Psoriasis severity is a presumed risk factor for development of psoriatic arthritis (PsA) but most studies have examined this question retrospectively. Additionally, it remains unclear whether obesity and body surface area of psoriasis (BSA) are independent risk factors for PsA. Objectives: We examined the association of psoriasis severity, obesity and other potential risk factors for the development of PsA in patients with psoriasis.

Methods: Between 2008-2011, patients with at least one code for psoriasis aged 25-60 years in The Health Improvement Network were randomly selected and questionnaires were sent to their general practitioners (GPS). GPs were asked to confirm the diagnosis of psoriasis and provide the patient's approximate BSA that the patient typically demonstrates based on categories commonly used for epidemiological studies. Data through 2015 were used in the current analysis. After excluding patients with PsA at baseline, the incidence of PsA among patients with psoriasis was calculated. Cox proportional hazard ratios were used to examine the risk of developing PsA among patients with mild $(<3 \%)$, moderate (3$10 \%$ ) and severe $(>10 \%)$ psoriasis. We also examined other covariates including obesity, depression, recent infections, smoking, and comorbidities in univariable models. Factors significant at the unviariable level were included in multivariable models. We additionally tested an interaction between BSA and obesity.

Results: Among 10,474 questionnaires sent, 9,987 (95\%) were returned and, of those, $9,069(91 \%)$ had confirmed psoriasis. The mean age was 46 and $53 \%$ were female. BSA was provided for 8,881 patients of which $52 \%$ had mild psoriasis, $36 \%$ moderate psoriasis, and $12 \%$ severe psoriasis. Mean follow up time was 4.2 years (SD 2.1); the incidence of PsA was 5.4 cases per 1,000 person years. In univariable models, age and sex were not associated with PsA but obesity, BMI (continuous), BSA (continuous and category) and depression were significantly associated with development of PsA. The final multivariable model included BSA category (ref mild, moderate: HR 1.44, 95\% Cl: 1.02-2.03; severe HR 1.99, 1.28-3.11), history of depression (1.69, 1.22-2.34), obesity (1.64, 1.192.25), age (HR 0.99, 0.98-1.00) and female sex (HR 0.72, 0.52-0.99). There was not a statistically significant interaction between BSA and obesity although patients that were obese and had $\geq 10 \%$ BSA had the highest risk (HR 3.90, 2.22-6.85).

Conclusion: In this large prospective cohort study, we found that body surface area is a strong predictor of developing psoriasis over the next 4-7 years and obesity is an additive risk factor.

REFERENCES:

[1] Scher JU, et al. Nat Rev Rheumatol 2019 In Press.

Acknowledgement: Funded by NIH/NIAMS K23 AR063764

Disclosure of Interests: Alexis Ogdie Grant/research support from: (To my university) Novartis, Pfizer, Grant/research support from: Novartis, Pfizer,
Grant/research support from: Novartis, Pfizer, Grant/research support from: Novartis, Pfizer, Consultant for: AbbVie, Bristol-Myers Squibb, Celgene, Corrona, Eli Lilly and Company, Novartis, Pfizer, and Takeda, Consultan for: AbbVie, Amgen, Bristol-Myers Squibb, Celgene, Corrona, Eli Lilly, Novartis, Pfizer Inc, Takeda, Consultant for: Abbvie, Amgen, BMS, Celgene, Corrona, Lilly, Novartis, Pfizer, Takeda, Consultant for: Abbvie, Amgen, BMS, Celgene, Corrona, Lilly, Novartis, Pfizer, Takeda, Danie Shin: None declared, Hyon Choi: None declared, Christopher T. Ritchlin Grant/research support from: AbbVie, Amgen, UCB Pharma, Consultant for: AbbVie, Amgen, Lilly, Novartis, Pfizer, UCB Pharma, Joseph F. Merola Consultant for: Biogen IDEC, Abbvie, Amgen, Eli Lilly and Company, Novartis, Pfizer, Janssen, UCB, Samumed, Celgene, Sanofi Regeneron, Merck, and GSK, Jose Scher Grant/research support from: Pfizer, Novartis, Consultant for: Janssen, UCB, Novartis, Amgen, Thorvardur Jon Love Consultant for: Received reimbursment from Celgene for speaking about guidelines for the treatment of psoriatic arthritis, Joel Gelfand Grant/ research support from: Research grants (to the Trustees of the University of Pennsylvania) from Abbvie, Boehringer Ingelheim, Janssen, Novartis Corp, Celgene, Ortho Dermatologics, and Pfizer Inc., Consultant for: BMS, Boehringer Ingelheim, Janssen Biologics, Novartis Corp, UCB (DSMB), Sanofi, and Pfizer Inc., Paid instructor for: Received payment for continuing medical education work related to psoriasis that was supported indirectly by Lilly, Ortho Dermatologics and Novartis.

DOI: 10.1136/annrheumdis-2019-eular.4991

\begin{tabular}{lcc}
\hline & Univariable & Multivariable \\
\hline Age & HR (95\% Cl) & HR (95\% Cl) \\
Female Sex & $0.99(0.98-1.00)$ & $0.99(0.98-1.00)$ \\
Body Mass Index (per 1 unit) & $0.83(0.63-1.09)$ & $0.72(0.52-0.99)$ \\
Obese BMI (BMl>30 vs <=30) & $1.04(1.02-1.07)$ & \\
Smoking & $1.62(1.20-2.17)$ & $1.64(1.19-2.25)$ \\
Never & Ref & \\
Current & $0.90(0.64-1.27)$ & \\
Past & $1.30(0.95-1.79)$ & \\
Body Surface Area Category & & $1.44(1.02-2.03)$ \\
Mild $(<3)$ & Ref & \\
Moderate (3-10) & $1.55(1.13-2.14)$ & \\
Severe $(>10)$ & $2.40(1.60-3.59)$ & \\
Anxiety & $0.94(0.67-1.32)$ & \\
Depression & $1.45(1.09-1.92)$ & \\
Any diarrheal illness & $1.28(0.93-1.75)$ & \\
Disabled & $1.41(0.75-2.67)$ & \\
Prior light therapy & $2.29(1.33-3.93)$ & \\
Hyperlipidemia & $0.94(0.60-1.48)$ & \\
Hypertension & $1.04(0.72-1.49)$ & \\
Diabetes & $0.72(0.40-1.30)$ & \\
\hline
\end{tabular}

\section{FRI0459 PREVALENCE OF DISEASE DOMAIN PRESENTATIONS AMONG PATIENTS WITH PSORIATIC ARTHRITIS: RESULTS FROM THE CORRONA PSORIATIC ARTHRITIS/SPONDYLOARTHRITIS (PSA/SPA) REGISTRY}

Alexis Ogdie $^{1}$, Peter Hur ${ }^{2}$, Mei Liu ${ }^{3}$, Sabrina Rebello ${ }^{3}$, Robert Mclean ${ }^{3}$ Blessing Dube ${ }^{3}$, Meghan Glynn ${ }^{3}$, Philip J. Mease ${ }^{4}$. ${ }^{1}$ Perelman School of Medicine at the University of Pennsylvania, Philadelphia, United States of America; ${ }^{2}$ Novartis Pharmaceuticals Corporation, East Hanover, United States of America; ${ }^{3}$ Corrona, LLC, Waltham, United States of America; ${ }^{4}$ Swedish Medical Center/Providence St. Joseph Health and University of Washington, Seattle, United States of America

Background: Psoriatic arthritis (PsA) is a heterogeneous, chronic inflam matory disease of the skin and musculoskeletal system. Six key domains of PsA have been identified to help guide treatment: peripheral arthritis, axial disease, enthesitis, dactylitis, and psoriatic skin and nail disease. Understanding the epidemiology of these different disease presentations is important for the management and treatment of PsA, yet there is limited evidence available.

Objectives: To describe the prevalence of disease domain presentations among patients with PsA at enrollment in the Corrona PsA/SpA Registry. Methods: This study included adult patients with PsA enrolled in the Cor rona PsA/SpA Registry between March 2013 and August 2018. Patients were evaluated for the presence of 6 disease domains at enrollment: enthesitis (Spondyloarthritis Research Consortium of Canada enthesitis count $>0$ ), dactylitis (dactylitis count $>0$ ), peripheral arthritis (PA; tender and/or swollen joint count $>0$ ), nail psoriasis (global nail psoriasis visua analog scale $>0$ ), axial disease (physician-reported presence of spina involvement, based on clinical judgment and/or radiographs or MRI showing sacroiliitis), and skin disease (BSA > 0\%). The most common mutually exclusive disease presentations were summarized among all patients 
with PsA and those who initiated biologics using frequency counts and percentages.

Results: Of 2617 patients with PsA enrolled in the Corrona PsA/SpA Registry, 1698 patients (64.9\%) had multidomain disease presentations, $617(23.6 \%)$ had single-domain presentations, and $302(11.5 \%)$ had no presentations. Overall, $1814(69.3 \%)$ patients presented with skin disease, $1523(68.2 \%)$ with PA, 1042 (39.8\%) with nail psoriasis, 539 (20.6\%) with enthesitis, 319 (12.2\%) with axial disease, and 235 (9.0\%) with dactylitis at enrollment. Among all patients with PsA, the most common disease presentations were skin disease (2.7\%), PA + skin disease (11.7\%), and PA + nail psoriasis + skin disease (10.3\%) (Figure 1).. A total of 354 patients initiated biologics at enrollment. Of these, 289 patients $(81.6 \%)$ had multidomain disease presentations, 45 (12.7\%) had singledomain presentations, and $20(5.6 \%)$ had no presentations; 273 patients (77.1\%) presented with PA, 267 (75.4\%) with skin disease, 159 (44.9\%) with nail psoriasis, $115(32.5 \%)$ with enthesitis, 70 (19.8\%) with dactylitis, and $64(18.1 \%)$ with axial disease at enrollment. The most common disease presentations were PA + nail psoriasis + skin disease (11.6\%), PA + skin disease $(11.3 \%)$, and enthesitis + PA + nail psoriasis + skin disease $(8.8 \%)$, and enthesitis + PA + skin disease (5.9\%) (Figure 2).

Conclusion: The majority of patients with PsA presented with multiple disease domains. Biologic initiators generally had a higher prevalence of all disease features. These results may increase the physician awareness of the heterogeneity of disease presentations among patients with PsA, which can be important for the development of an effective management plan.
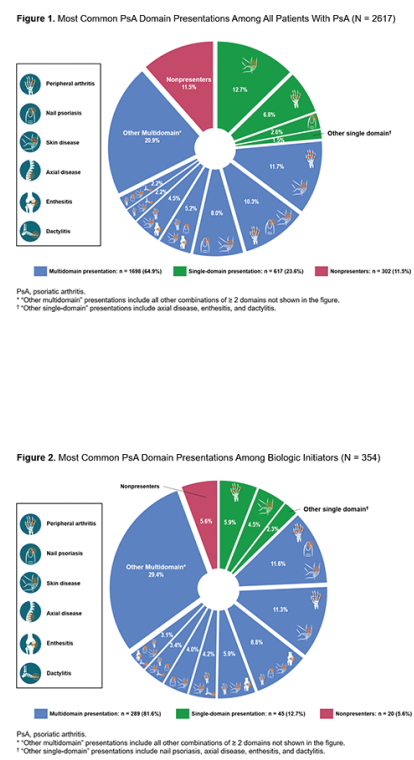

REFERENCES:

[1] Coates LC, et al. Arthritis Rheumatol. 2016;68(5):1060-71.

Acknowledgement: This study was sponsored by Corrona, LLC. Corrona is supported through contracted subscriptions with multiple pharmaceutical companies. The abstract was a collaborative effort between Corrona and Novartis, with financial support provided by Novartis.

Disclosure of Interests: Alexis Ogdie Grant/research support from: (To my university) Novartis, Pfizer, Grant/research support from: Novartis, Pfizer, Grant/research support from: Novartis, Pfizer, Grant/research support from: Novartis, Pfizer, Consultant for: AbbVie, Bristol-Myers Squibb, Celgene, Corrona, Eli Lilly and Company, Novartis, Pfizer, and Takeda, Consultant for: AbbVie, Amgen, Bristol-Myers Squibb, Celgene, Corrona, Eli Lilly, Novartis, Pfizer Inc, Takeda, Consultant for: Abbvie, Amgen, BMS, Celgene, Corrona, Lilly, Novartis, Pfizer, Takeda, Consultant for: Abbvie, Amgen, BMS, Celgene, Corrona, Lilly, Novartis, Pfizer, Takeda, Peter Hur Employee of: Peter Hur is an employee of Novartis Pharmaceuticals Corporation, East Hanover, New Jersey, USA, Mei Liu Employee of: M. Liu is an employee of Corrona, LLC., Sabrina Rebello Employee of: Corrona, LLC, Robert McLean: None declared, Blessing Dube Employee of: B.
Dube is an employee of Corrona, LLC., Meghan Glynn Employee of: M. Glynn is an employee of Corrona, LLC., Philip J Mease Grant/research support from: AbbVie, Amgen, BMS, Celgene, Janssen, Lilly, Novartis, Pfizer, SUN and UCB, Consultant for: AbbVie, Amgen, BMS, Galapagos, Gilead Sciences, Inc., Janssen, Lilly, Novartis, Pfizer, SUN and UCB Speakers bureau: AbbVie, Amgen, BMS, Celgene, Genentech, Janssen, Lilly, Novartis, Pfizer and UCB

DOI: 10.1136/annrheumdis-2019-eular.502

\section{\begin{tabular}{|l|l}
\hline FRI0460 IMPACT OF MULTIDOMAIN DISEASE PRESENTATIONS \\
\hline
\end{tabular} ON OVERALL DISEASE BURDEN AMONG PATIENTS WITH PSORIATIC ARTHRITIS: RESULTS FROM THE CORRONA PSORIATIC ARTHRITIS/ SPONDYLOARTHRITIS (PSA/SPA) REGISTRY}

Alexis Ogdie ${ }^{1}$, Peter Hur², Mei Liu ${ }^{3}$, Sabrina Rebello ${ }^{3}$, Robert Mclean ${ }^{3}$, Blessing Dube ${ }^{3}$, Meghan Glynn ${ }^{3}$, Philip J. Mease ${ }^{4} .{ }^{1}$ Perelman School of Medicine at the University of Pennsylvania, Philadelphia, United States of America; ${ }^{2}$ Novartis Pharmaceuticals Corporation, East Hanover, United States of America; ${ }^{3}$ Corrona, LLC, Waltham, United States of America; ${ }^{4}$ Swedish Medical Center/Providence St. Joseph Health and University of Washington, Seattle, United States of America

Background: Psoriatic arthritis (PsA) is a chronic inflammatory disease with heterogeneous presentations that may involve peripheral arthritis axial disease, enthesitis, dactylitis, and psoriatic skin and nail disease, either alone or in combination. Prior studies have characterized patients affected in one domain ${ }^{1,2}$; however, there is limited evidence in understanding the differential impact of multidomain vs single-domain presentations on the overall disease burden in PsA

Objectives: To compare disease characteristics, quality of life, and work productivity at enrollment among patients with PsA who have multidomain vs single-domain presentations in the Corrona PsA/SpA Registry.

Methods: This study included adult patients with PsA enrolled in the Corrona PsA/SpA Registry between March 2013 and August 2018. Patients were evaluated for the presence of 6 disease domains at enrollment: enthesitis (SPARCC enthesitis count $>0$ ), dactylitis (dactylitis count $>0$ ), peripheral arthritis (PA; tender and/or swollen joint count $>0$ ), nail psoriasis (global nail psoriasis VAS > 0), axial disease (physician-reported presence of spinal involvement, based on clinical judgment and/or radiographs or MRI showing sacroiliitis), and skin disease (BSA > $0 \%$ ), and were further classified as having multidomain or single-domain disease presentations. Separate multivariable linear regression models evaluated the association of the presence of multidomain presentations with selected PsA disease characteristics, quality of life, and work productivity measures relative to single-domain presentations. Models were adjusted for age, sex, race, BMI, disease duration, and current and prior biologic, conventional synthetic disease-modifying antirheumatic drug, and prednisone use.

Results: Of 2315 patients with PsA enrolled in the Corrona PsA/SpA Registry who had $\geq 1$ disease domain presentation, 1698 patients (73.3\%) were classified as having multidomain disease presentations and $617(26.7 \%)$ as single-domain presentations. The most common singledomain and multidomain presentations, respectively, were skin disease $(12.7 \%)$ and $\mathrm{PA}+$ skin disease $(11.7 \%)$. At enrollment, patients with multidomain presentations had higher BMl; shorter disease duration; were more likely to have fibromyalgia, depression, and anxiety; and were more likely to have prior biologic use vs those with single-domain presentations (Table 1). In adjusted analyses, the presence of multidomain presentations was associated with significantly worse patient and physician global assessment of disease, pain, fatigue, HAQ-DI and EQ-5D scores, and work productivity and activity at enrollment (Table 2).

Conclusion: In this US real-world cohort, nearly three-quarters of patients with PsA had multidomain disease presentations, which were associated with worse disease activity, quality of life, and work productivity measures compared with single-domain disease presentations. Assessing all PsA domains is critical for developing a comprehensive management plan and reducing the impact of PsA on patients' lives.

\section{REFERENCES:}

[1] Mease PJ, et al. Arthritis Care Res (Hoboken). 2017;69(11):1692-9.

[2] Mease PJ, et al. J Rheumatol. 2018;45(10):1389-96.

Acknowledgement: This study was sponsored by Corrona, LLC. Corrona is supported through contracted subscriptions with multiple pharmaceutical 